\title{
Use and Attitudes towards Teleconsultation in Dentistry
}

\author{
Eino Ignatius $^{1}$, K. Mäkelä ${ }^{1,2}$ \\ ${ }^{1}$ Seinäjoki Central Hospital, Seinäjoki, Finland \\ ${ }^{2}$ Tampere University of Technology, Tampere, Finland \\ Email: eino.ignatius@epshp.fi
}

Received November 9, 2012; revised December 12, 2012; accepted December 22, 2012

\begin{abstract}
An electronic (web-based) questionnaire was devised to find out the extent of teleconsultation and e-mail use for patient-provided communications in dentistry. This project was carried out in 2011 in the health care district of SouthOstrobothnia, in South-Western Finland. The questionnaire was sent by e-mail to all 120 regional dentists, to which 76 replies were obtained (response rate 63\%). The responses indicated a surprisingly positive attitude towards teleconsultation. A clear majority of $91 \%$ indicated that it could bring additional benefits to the current consultation methods. This study revealed that a slight majority of dentists in the region use e-mail for patient communication and 53\% used e-mail for consultation. Approximately $10 \%$ use videoconferencing for consultation. The study also revealed that the majority of those who do not yet use electronic consultation are willing to try them out in the future. Security issues are a concern for many dentists. Practically all respondents wish for written instructions on the use of electronic consultation.
\end{abstract}

Keywords: Teledentistry; Teleconsultation; E-Mail; Patient-Provider Communication; Computer-Assisted Dentistry

\section{Introduction}

Before ICT (information and communications technology) solutions became more widespread also in dentistry, dentists commonly consulted each other on the phone without visual contact, or by sending each other different types of patient documentation (patient medical histories, $\mathrm{x}$-rays images on film, cast models, etc.).

The use of unprotected e-mail for patient-provider communications has been studied since the early 1990's in the USA [1,2]. After this, several studies have been carried out on the use of e-mail in patient-provider communication [3-7]. A report documenting the state of electronic patient record systems and their use in Finnish health care in general was published in 2004 [8]. There are, however, very few such studies concerning dentistry.

There was previous experiences on the use of videoconferencing in dentistry in the region of South-Ostrobothnia in Finland. We have carried out several teledentistry projects in the region; the use and suitability of videoconferencing for dental consultation was also studied in a research project in 2008-2009 [9]. These projects have resulted in an increased use of dental teleconsultations.

The purpose of this study was to determine how common the use of e-mail and videoconferencing is currently amongst dentists in the South-Ostrobothnia region and what attitudes and specific needs exist amongst dentists regarding electronic consultation.

\section{Methods}

This project was carried out in 2011 in the Seinäjoki area (South-Ostrobothnia Health District) in Finland. The study region is relatively large in size, but sparsely populated. The total population of the South-Ostrobothnia Health District is about 215,000.

Everyone is entitled to municipal dental services, which is completely free until the age of 18 , after which a small fee is charged for dental services. In addition to community dental services, there are also approximately 40 private dental practitioner is the county. Together with the community dental professionals, they form the primary dental services available in the county. Primary care dental practitioners can refer their patients to secondary care to Department of Oral and Maxillofacial diseases of Seinäjoki Central for more demanding treatment.

Based on the referral, the patient commonly comes in for a polyclinic visit to the hospital. Based on this visit, follow-up treatment is decided on. By using electronic referrals, in some cases the follow up treatment can been decided on without the need for a patient visit and the patient can been referred to the correct treatment or department based on electronic referral data only [9].

An electronic (web-based) WebPropol questionnaire was devised to determine what types of electronic consultation tools and methods are currently in use in dental consultation and patient-provider communication in the 
region. We also wanted to find out the state and use of use of electronic data bases in dental clinics and in patient work, and what are the dentist's attitudes towards use of electronic consultation and patient communications. The skills possessed by dentists to use different types of digital tools, and possible needs for training, was also asked about.

Data security issues and the respondents' knowledge in this field was queried as well as opinions about what principles should be used to obtain sufficient data security in clinical practice in the future.

The questionnaire was sent to all 120 dental practitioners in the region, both in the public and private sector. Reminder messages were sent one month after the initial contact.

\section{Results}

The questionnaire was sent by e-mail to 120 dentists, and 76 replies were obtained (response rate 63\%). Respondents worked either in public healthcare, in the private sector as private dentists or in the Central Hospital directly or as consultants for the hospital (Table 1).

Table 2 showed that E-mail was used by 30\% of the dentists for patient-provided communications, 53\% used e-mail for consultation. Videoconferencing was used by $10 \%$ for consultation purposes. The use of videoconferencing was at a low level though, only 1 - 5 consultations per month were performed by these methods. Not a single respondent used these consultation methods more often than 5 times a month. Of those dentists that used e-mail for consultation also used clinical digital images (photographs) and digital $\mathrm{x}$-ray images as attached files (Table 3). 55\% of the respondents expect to receive the replies to the electronic consultations within $2-3$ days (Table 4).

Meanwhile, a majority of 58\% of the respondents who do not yet use e-mail for consultation indicated that they were willing to do so in the future. Of those not yet using videoconferencing, $34 \%$ indicated a willingness to do so in the future. A significant majority of $88 \%$ indicated a willingness to participate in training for the use of electronic consultation methods (Table 5).

A slim majority of 52\% were prepared to pay for electronic consultation. A digital camera suitable for consultation was available in $64 \%$ of the clinics. The equipment needed to obtain digital images of the entire mouth area (teeth and jaws OPTG-imaging), was in $76 \%$ of the clinics.

Practically all respondents who do not know how to attach clinical digital images or digital $\mathrm{x}$-ray images to their e-mail messages indicated that they were willing to learn to do so. Only 5\% indicated that this is not necessary.

In addition to electronic consultation and patient referral to secondary care, the respondents currently utilize the following types of consultation in Table 6 .

Other consultation methods included joint meetings by dentists, specialist dentist phone consultation and clinical specialist consultation. Electronic consultation could replace current (traditional) consultation methods according to $49 \%$ of respondents, and a clear majority of $91 \%$ indicated that electronic consultation could bring additional benefits to the current, non-electronic consultation methods.

The dentists were also queried on data security issues, the responses to the questions are shown in Table $\mathbf{7 .}$

Table 1. Answerers position.

\begin{tabular}{ccc}
\hline Public health care & $66 \%$ & 50 \\
Private sector & $24 \%$ & 18 \\
Hospital & $10 \%$ & 8 \\
\hline
\end{tabular}

Table 2. E-mail using for.

\begin{tabular}{cc}
\hline Patient-provided communication & $30 \%$ \\
Consultation & $53 \%$ \\
\hline
\end{tabular}

Table 3. E-mail users attached.

\begin{tabular}{cc}
\hline Digital photographs & $41 \%$ \\
Digital x-ray images & $78 \%$ \\
\hline
\end{tabular}

Table 4. Replies to the electronic consultations queries the respondents expected to receive within.

\begin{tabular}{cc}
\hline The same day & $10 \%$ \\
Within 2 - 3 days & $55 \%$ \\
Within a week & $34 \%$ \\
\hline
\end{tabular}

Table 5. Willingness to participate in the future (those who didn't use yet).

\begin{tabular}{cc}
\hline E-mail consultation & $58 \%$ \\
Videoconferencing consultation & $34 \%$ \\
Training for electronic consultation & $88 \%$ \\
\hline
\end{tabular}

Table 6. Different types of consultation using for.

\begin{tabular}{cc}
\hline Another dentist present at the clinic & $75 \%$ \\
A specialist dentist of same employer & $41 \%$ \\
External consult (specialist dentist) visits the clinic & $22 \%$ \\
Show cast models and x-rays to outside consultant & $16 \%$ \\
Some other method & $8 \%$ \\
Does not use other consultation methods & $7 \%$ \\
\hline
\end{tabular}


Table 7. Dentists' opinions concerning data security issues in electronic dental consultation.

\begin{tabular}{|c|c|c|c|c|c|c|}
\hline Score 1 - 4 & $\begin{array}{l}\text { 1: agree } \\
\text { completely }\end{array}$ & $\begin{array}{l}\text { 2: agree } \\
\text { mostly }\end{array}$ & $\begin{array}{l}\text { 3: disagree } \\
\text { mostly }\end{array}$ & $\begin{array}{l}\text { 4: disagree } \\
\text { completely }\end{array}$ & $\begin{array}{l}0: \text { cannot } \\
\text { say }\end{array}$ & $\begin{array}{l}\text { Average } \\
\text { score }\end{array}$ \\
\hline $\begin{array}{l}\text { Present data security of e-mail is sufficient for } \\
\text { patient-provider communications. }\end{array}$ & $19.2 \%$ & $24.7 \%$ & $28.8 \%$ & $16.4 \%$ & $11 \%$ & 2.5 \\
\hline $\begin{array}{l}\text { Present data security of e-mail is sufficient for consultation } \\
\text { that includes patient identification. }\end{array}$ & $6.8 \%$ & $16.4 \%$ & $26 \%$ & $41.1 \%$ & $9.6 \%$ & 3.2 \\
\hline $\begin{array}{l}\text { Present data security of e-mail is sufficient for consultation } \\
\text { without including patient identification. }\end{array}$ & $36.5 \%$ & $35.1 \%$ & $16.2 \%$ & $5.4 \%$ & $6.8 \%$ & 1.9 \\
\hline $\begin{array}{l}\text { If a dentist wishes to use e-mail for patient communication, } \\
\text { this has to be agreed upon beforehand with the patient. }\end{array}$ & $74.3 \%$ & $16.2 \%$ & $5.4 \%$ & $2.7 \%$ & $1.4 \%$ & 1.4 \\
\hline $\begin{array}{l}\text { If a dentist wishes to use e-mail for consultation purposes, } \\
\text { this has to be agreed upon beforehand with the patient. }\end{array}$ & $53.4 \%$ & $19.2 \%$ & $16.4 \%$ & $8.2 \%$ & $2.7 \%$ & 1.8 \\
\hline $\begin{array}{l}\text { Dentists need written instructions and generally agreed } \\
\text { upon principles for the use of e-mail and videoconferencing } \\
\text { in patient communications and consultations. }\end{array}$ & $78.4 \%$ & $17.6 \%$ & $1.4 \%$ & $0 \%$ & $2.7 \%$ & 1.2 \\
\hline
\end{tabular}

Half of the respondents (50\%) indicated that they had enough time within their present work routines for electronic consultation and to take care of patient contacting by e-mail.

Some suggestions concerning new types of electronic consultation forms that could be implemented, included more contacts between dentists in private sector and those in health care centres, short training lessons as video streams to their clinic or home PC and video consultations to several sites simultaneously.

In addition, the respondents indicated a need for additional training in digital photography and of different forms of electronic consultation. The level of competence of those participating in these training sessions should be determined in advance and training at different levels of pre-required competence should be offered.

\section{Discussion and Conclusions}

The use of teleconsultation and e-mail is a relatively new research area in dentistry. Much of the terminology in use has not "matured" and is therefore not universally accepted or agreed on; different usage of terminology may have a negative impact when gathering data and therefore poses challenges in its own. It is also possible that this is one reason that some of the most pertinent scientific articles in this topic may not reach all those interested in this field. Agreeing on the use and terminology in teleconsultation in dentistry should therefore be one of the next aims in dentistry.

The study region in this project represents a relatively typical Finish health district, hence it can be assumed that the results of this study can be applied nationally and most likely gives a good representation of national approach to telemedicine by Finnish dentists.

No systematic training in teledentistry is given at any national university, presently training in this field to dentists is limited to seminars and infrequent local courses. One future aim should be to improve this situation and cater to the numerous request for additional training that were evident in this study.

There are many regions in Finland with insufficient number of skilled specialist dentists. Teledentistry could in part alleviate this continually growing shortage, especially in the more sparsely populated regions.

There are no nationally ratified regulations for the use of e-mail in patient-provider communications or consultation; there are however recommendations given by the Finnish medial association in its ethics rules from 2007. In these, e-mail is mentioned as one tool for patient-provider communications. The terms used in the recommendations, for instance: "sufficiently strong encryption" and "identity verifiable with confidence", do not necessarily mean anything for persons that have obtained training as physicians or dentists. It cannot be assumed that based on these recommendations, a single professional could set up relevant teleconsultation channels. Hence, more co-operation between different professionals is needed.

We ensured the rationality of the items of data security issues in the Table 7 first with smaller pilot group. Positive feedback and experiences of earlier studies cultivated our query.

It appears that the majority of dentists have a positive attitude towards ICT-based solutions and tools that can be used in consultation and patient communications. The majority of dentists appear to believe that these would bring added benefits to daily routines. However, at present, even though a significant number of dentists appear to routinely use some form of electronic communication tool for consultation or patient communications, the number of patient cases where these are used are typi- 
cally only 1 - 5 per month. This seems to signify that although the basic infrastructure is largely present, teleconsultation in dentistry is at its early stages yet.

A major problem appears to be lack of information on how to use electronic communications channels effectively and safely. Because of this, more training in this field should be provided to dentists as part of their specialist training programme and make it also part of basic dental training in the future.

\section{Acknowledgements}

This project was funded by Seinäjoki Central Hospital research foundation.

\section{REFERENCES}

[1] D. B. Fridsma, et al., "A Survey of Patient Access to Electronic Mail: Attitudes, Barriers and Opportunities,” Proceedings of Annual Symposium on Computer Application in Medical Care, 1994, pp. 15-19.

[2] R. A. Neill, et al., "The Utility of Electronic Mail as a Medium for Patient-Physician Communication,” Archives of Family Medicine, Vol. 3, No. 3, 1994, pp. 268-271. doi:10.1001/archfami.3.3.268

[3] E. Ignatius, K. Mäkelä and S. Perälä, “Computer Assisted Consultation in Dental Practice,” Finnish Dental Journal,
Vol. 16, 2003, pp. 864-868.

[4] C. Baur, "Limiting Factors on the Transformative Powers of E-Mail in Patient-Physician Relationships: A Critical Analysis,” Health Communication, Vol. 12, No. 3, 2000, pp. 239-259. doi:10.1207/S15327027HC1203_02

[5] R. G. Brooks and N. Menachemi, "Physician Use of EMail with Patients: Factors Influencing Electronic Communication and Adherence to Best Practices,” Journal of Medical Internet Research, Vol. 8, 2006, p. e2. doi:10.2196/jmir.8.1.e2

[6] W. A. Christmas, et al., "Should College Health Providers Use E-Mail to Communicate with Their Patients? Two Points of View," Journal of American College Health, Vol. 49, No. 1, 2000, pp. 39-43. doi:10.1080/07448480009596281

[7] T. Delbanco and D. Z. Sands, "Electrons in Fight-EMail between Doctors and Patients," New England Journal of Medicine, Vol. 350, 2004, pp. 1705-1707.

[8] K. Kiviaho, J. Winblad and J. Reponen, “Terveydenhuollon Toimintaprosesseja Ja Asiointia Tukevat AtkSovellukset Suomessa. Sosiaali-Ja terveysalan Osaavien Keskusten Verkoston Julkaisuja,” Stakesin monistamo, Helsinki, 2004.

[9] E. Ignatius, S. Perälä and K. Mäkelä, "Use of Videoconferencing for Consultation in Dental Prosthetics and Oral Rehabilitation," Journal of Telemedicine and Telecare, Vol. 16, No. 8, 2010, pp. 467-470. doi:10.1258/jtt.2010.100303 